\title{
Work Hardening of Non-Axisymmetric Die-Less Spinning
}

\author{
Zhen Jia ${ }^{1}$ - Zhiren Han ${ }^{1, *}$ - Baoming Liu ${ }^{1}$ - Yong Xiao ${ }^{2}$ \\ 1 Shenyang Aerospace University, Key Lab of Fundamental Science \\ for National Defence of Aeronautical Digital Manufacturing Process, China \\ ${ }^{2}$ Northwestern Polytechnical University, School of Mechanical Engineering, China
}

\begin{abstract}
Non-axisymmetric shell parts are widely used in the fields of aviation, aerospace and automobiles. Because of good flexibility, short production preparation period and low cost, die-less spinning has the advantages in processing those parts. However, the special work-hardening distribution being caused by its processing technology will affect the performance of these parts. Therefore, the work-hardening of nonaxisymmetric die-less spinning is studied through experiments and by using the finite element method (FEM). The law of "smaller half cone angle (HCA) with bigger work-hardening" is found by testing the surface hardness of the spun workpieces. Microstructure observation and theoretical analyses are adopted to reveal the law. The reason for that is that the roller causes greater plastic strain inhomogeneity in the smaller HCA-forming process. It is also found that the working condition with the largest HCA difference has the biggest work-hardening difference and the maximum hardness difference can be $15 \%$.
\end{abstract}

Keywords: non-axisymmetric spinning, work-hardening status, die-less spinning, HCA, FEM, strain

Highlights

- $\quad$ Because of the effect of the special work-hardening distribution being caused by the non-axisymmetric die-less spinning process on the strength of non-axisymmetric shell parts, the work-hardening of non-axisymmetric die-less spinning is studied through experiments and by using FEM.

- Three working conditions of non-axisymmetric die-less spinning experiments are carried out with the deduced roller path. The work-hardening distributions of the workpieces are obtained via the surface hardness testing.

- The law "smaller half cone angle (HCA) with bigger work-hardening" is found and can be applied to the HCAs on either one or several workpieces.

- $\quad$ The reason for the law is that the roller causes greater plastic strain inhomogeneity in the smaller HCA forming process.

\section{INTRODUCTION}

Spinning, a kind of metal forming technique, is commonly known as a process for transforming flat sheet metal blanks, usually with axisymmetric profiles, into hollow shapes by a tool which forces a blank onto a mandrel. Due to its flexible, stable, and near net-shape forming for axisymmetric parts, spinning is widely used in aerospace, chemical products, and special materials parts processing [1] to [3]. Previously, shell parts with non-axisymmetric shapes were mainly manufactured by welding two stamping parts whose shapes are the half of the nonaxisymmetric parts in the traditional process, such as automotive catalytic converters (see Fig. 1). Recently, with the development of the spinning technology, the non-axisymmetric tubular parts can be manufactured. Xia et al. [4] and [5] and Wia [6] developed a spinning method to produce a non-axisymmetric tube. The whole strength of the parts is significantly improved by the integrated forming method of spinning. In their investigations, the working principle, forming characteristics and deformation mechanism of the nonaxisymmetric tube spinning is discussed by adopting the finite element method (FEM) and experiments.
It shows that the distributions of strain, stress and thickness reduction of the non-axisymmetric tubular spun workpieces are non-axisymmetric and uneven. Awiszus and Härtel [7] and Härtel and Laue [8] investigate the spinning process for making noncircular parts by adopting modelling and experiment methods, and the process optimization has been proposed. Music and Allwood [9] put forward a flexible asymmetric spinning method by replacing the asymmetric mandrel with three rollers which can be controlled on a seven-axis machine. Sugita and Arai [10] investigate the effect of different parameters of the pass set on the formability in synchronous multipass spinning. The above-mentioned research results have laid a solid foundation for the asymmetric and non-circular cross-section spinning technology, and indicate that the uneven status of the force and the deformation forming during the non-axisymmetric or noncircular spinning processes will lead to different microstructures and thus cause different workhardening states. It is mainly because that the workhardening behaviour of the parts is closely related to the microstructure. Therefore, the microstructure evolution during the spinning process has been studied by many scholars in recent years. 
Zhan et al. [11] investigate the influence of the heating temperature on the hot shear spinning of TA15 alloy and conclude that the non-uniform deformation along the thickness direction leads to a non-uniform microstructure. The effect of the shear spinning on the deformation behavior and the microstructure of $\mathrm{AlMg}_{6} \mathrm{Mn}$ alloy was investigated by Radović et al. [12]. Yan et al. [13] and Xia et al. [14] and [15] investigated the effect of power spinning on the microstructure of the tubular part. They conclude that the average grain size of the ferrite can be reduced to $500 \mathrm{~nm}$ from the initial one of $50 \mu \mathrm{m}$ after the stagger spinning.

Die-less spinning means the parts are spun from a sheet blank without a mandrel die, which can enhance the cost reduction and shorten the production cycle for the non-axisymmetric spinning process. However, the force state of the process will be different from the one with the mandrel due to the lack of support to the blank. And this may result in special microstructure of the alloy and cause different work-hardening states which will reflect the strength [16] on the surface of the non-axisymmetric cone. Therefore, the workhardening state of the non-axisymmetric die-less spinning is investigated in this paper.

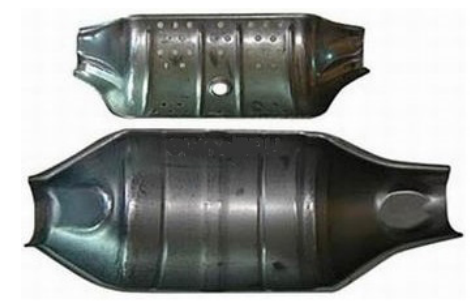

Fig. 1. Schematic diagram of automotive catalytic converter

\section{NON-AXISYMMETRIC SPINNING}

Fig. 2 shows the geometric model of a nonaxisymmetric cone. It can be seen that the cone is made up of countless thin circular sheets; the half cone angles (HCA) seen from the side view are different, and this means the lower cross section is an eccentric circle relative to the upper one; the relative eccentricity increases gradually with the increase of the height of the cone. The process of shear spinning is that the sheet blank rotates with the spindle and tail cap. The roller moves along a specific path and contacts the blank first and then forces the blank to form the desired shape without a mandrel. Based on the above conditions, a non-axisymmetric spinning is proposed: When the blank rotates a small angle $\Delta \theta$, the roller goes down from the upper sheet to the lower one along the axial direction. At the same time, the roller moves far away from the rotational centre along the radial direction, and moves towards the rotational centre after $90^{\circ}$ rotated by the blank. The roller goes straight down in the axial direction and switches to the radial direction in every $180^{\circ}$ of the rotation cycle. The radius of the circle in each sheet increases from top to bottom. Thus, a spiral trajectory with a gradually expanding radius is used for the roller path, and its mathematical expression (deduced in [17]) is:

$$
\begin{gathered}
x=-0.5 i f\left(\frac{\Delta \theta}{360}\right)(\tan \alpha-\tan \gamma) \cos \theta+ \\
+\sqrt{\left[R_{0}+0.5 i f\left(\frac{\Delta \theta}{360}\right)(\tan \alpha+\tan \gamma)\right]^{2}-} \\
z=-i f\left(\frac{\Delta \theta}{360}\right),
\end{gathered}
$$

where $x$ and $z$ are the radial and axial coordinates of the roller path, respectively. $R_{0}$ is the initial radius of the cross section; $\alpha$ and $\gamma$ are the co-angles of the maximum and minimum HCA (see Fig. 2) respectively; $\theta$ is the accumulation of $\Delta \theta ; f$ is the axial feed rate; and $i$, as a integer, is a global variable whenever the spindle rotates an angle increment $\Delta \theta$, and there is:

$$
\theta=i \Delta \theta
$$

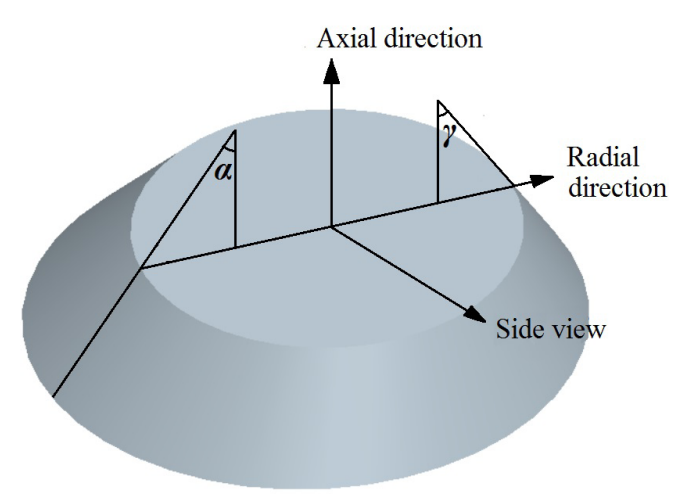

Fig. 2. Geometric model of non-axisymmetric cone

\section{EXPERIMENT AND ANALYSES}

\subsection{Spinning Experiment}

The working conditions of different HCAs in Table 1 are adopted for the spinning experiments. The material 
of the disk blank is 6061-O aluminium alloy, and the radius and thickness of the blank are $120 \mathrm{~mm}$ and 1.2 $\mathrm{mm}$, respectively. The initial radius $R_{0}$ is $25 \mathrm{~mm}$. The diameter of the roller is $110 \mathrm{~mm}$. The working radius of the roller is $2 \mathrm{~mm}$. The angle between the rotation axis of the roller and the axial direction of the spinning system is $45^{\circ}$. The axial feed rate $f$ is $0.3 \mathrm{~mm} / \mathrm{rev}$. The feed speed of the roller is $5000 \mathrm{~mm} / \mathrm{min}$. With the roller path equations, the non-axisymmetric spinning experiments are carried out on the PS-CNCSXY 5-axis spinning machine as shown in Fig. 3.

Table 1. Working conditions of the non-axisymmetric spinning

\begin{tabular}{lccc}
\hline HCA & Working condition I & Working condition II & Working condition III \\
\hline$\alpha\left[^{\circ}\right]$ & 45 & 60 & 60 \\
\hline$\gamma\left[^{\circ}\right]$ & 30 & 30 & 45 \\
\hline
\end{tabular}

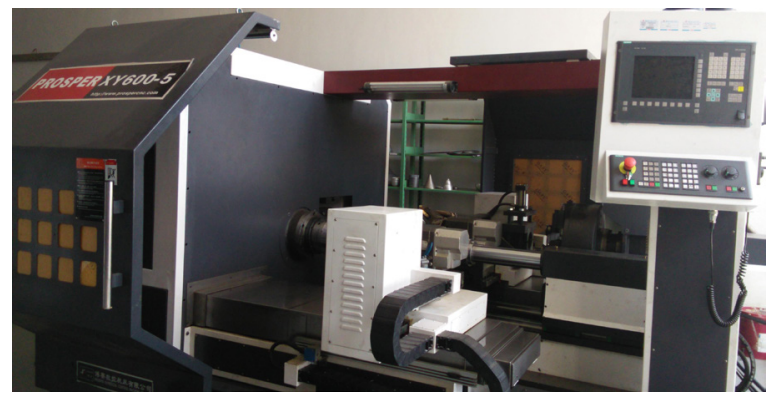

Fig. 3. PS-CNCSXY 5-axis spinning machine

The machine is a numerically-controlled (NC) one. It is driven by four servomotors (GS3050YNP2) which control the movements of the two rollers along axial and radial directions on both sides of the spindle, and the control accuracy can be $0.001 \mathrm{~mm}$. The roller path is executed by the combination motion of the spindle rotation and roller feed. The rotational velocity of the workpiece must match the movement of the roller through the $\mathrm{NC}$ system of the spinning machine. The experiment results are shown in Fig. 4.

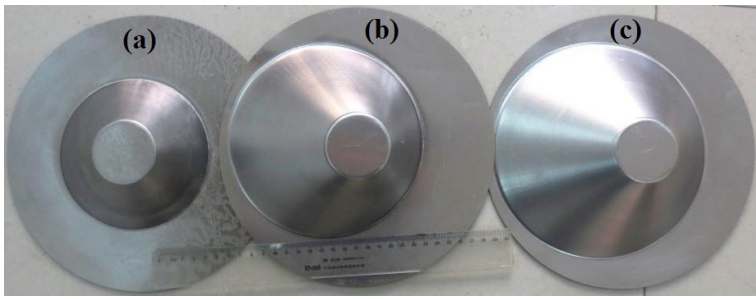

Fig. 4. Spun workpieces; a) working condition I; b) working condition II; c) working condition III

\subsection{Work-Hardening Distributions}

Three longitude directions $\left(0^{\circ}, 90^{\circ}\right.$ and $\left.180^{\circ}\right)$ and three latitudes (top, middle and bottom) are set on the spun workpieces as shown in Fig. 5. The intersections of the longitude lines and latitude lines can then be defined as 9 positions. In these positions, 9 specimens with the length and width $12 \mathrm{~mm} \times 8 \mathrm{~mm}$ are cut down from the workpiece (see Fig. 5). Then the hardness tests were carried out at three points, which are selected randomly on the surface of the specimens with the HVS-50 Vickers hardness tester (Fig. 6).

The average value of the hardness of the three measuring positions on each specimen is taken as the
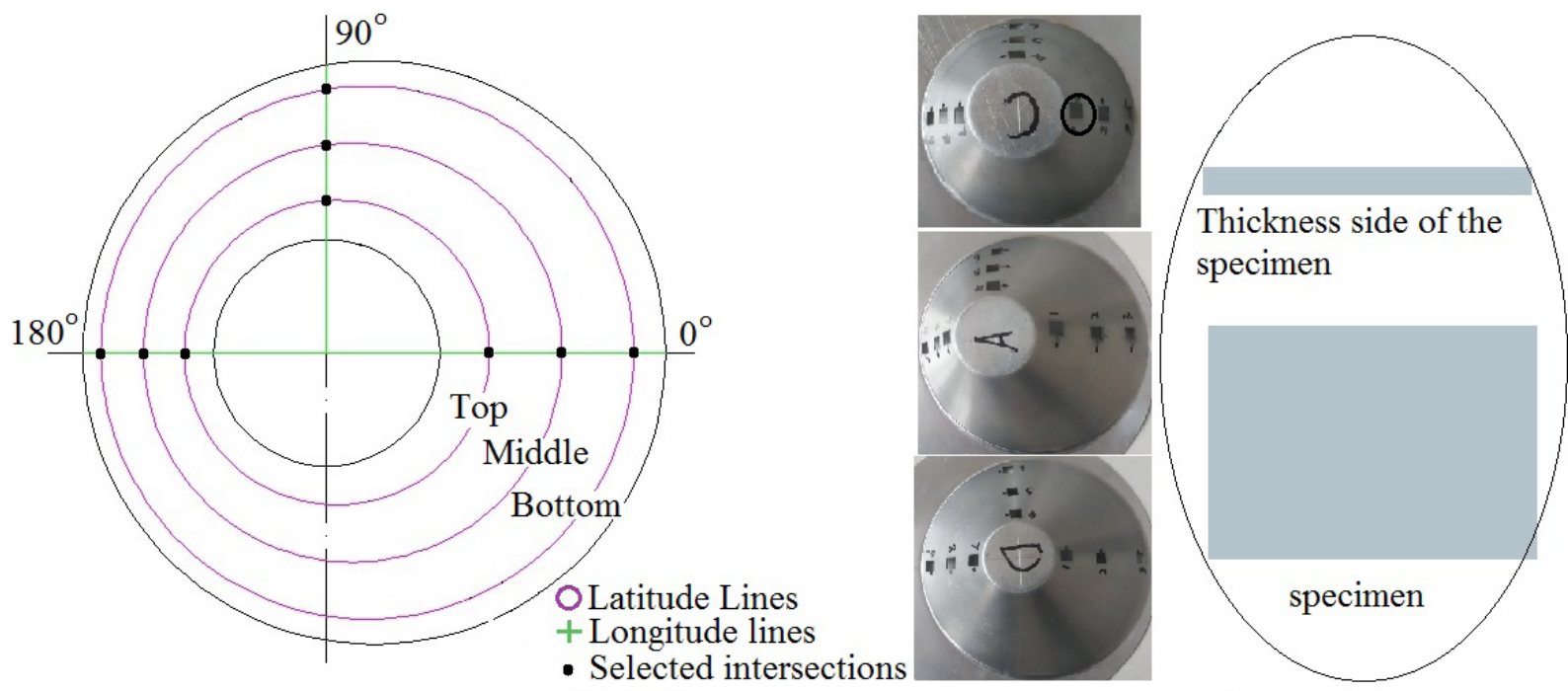

Fig. 5. Positions and shapes of the specimens 
hardness of the selected intersection (see Fig. 5), and the hardness of all the intersections is shown in Fig. 7. It can be found that small differences in the hardness exist in the specimens with the same HCA. However, there is an obvious tendency that the material with smaller HCA has greater surface hardness. This means the work-hardening distribution of non-axisymmetric die-less spinning is uneven, and bigger workhardening appears in the position with smaller HCA.

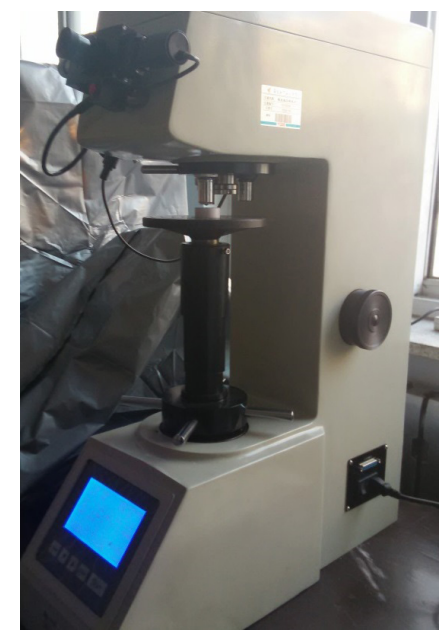

Fig. 6. HVS-50 Vickers hardness tester

The hardness of the parts is closely related to the microstructure. The microstructure of the specimens that were used for the hardness test is thus observed with an optical microscope. First, the thickness sides (Fig. 5) of the specimens are ground and polished. Then, all the smooth surfaces are corroded through the electrolysis method. Finally, the metallographic photos of the specimens are obtained as shown in Fig. 8. It can be found that the grain boundary of the workpiece is broken after two plastic deformations (one is the rolling aluminium alloy plate and the other is the spinning process) and many precipitates emerge. According to [18], the grain of 6061 aluminium alloy will be refined to a very small one and its boundary will also be broken after large plastic deformation. At the same time, the disorganized precipitates seriously hinder the observation of dislocations. Therefore, the metallographic method of the workpieces spun from the 6061 aluminium alloy sheet blank is not suitable for revealing work-hardening. However, the differences of the microstructure can be reflected by the macroscopic states of the stress and strain. Therefore, the finite element method is adopted to analyse the essence of the work-hardening distribution of the non-axisymmetric die-less spinning (the metal with smaller HCA has higher surface hardness).

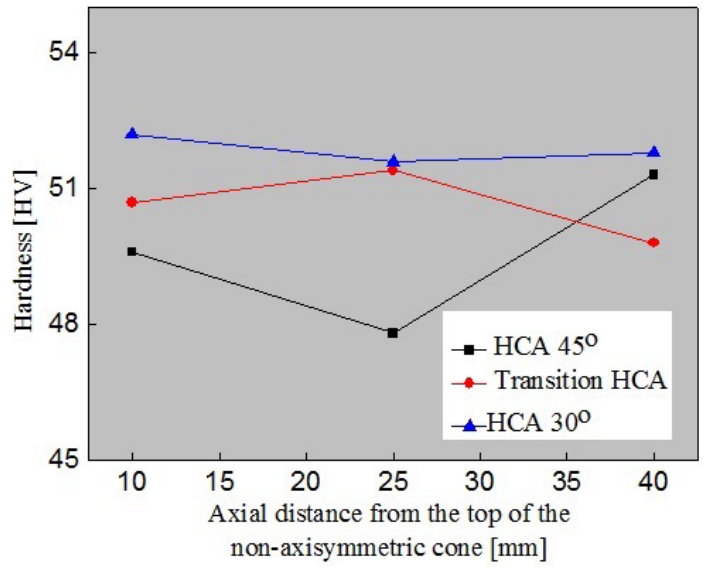

a)

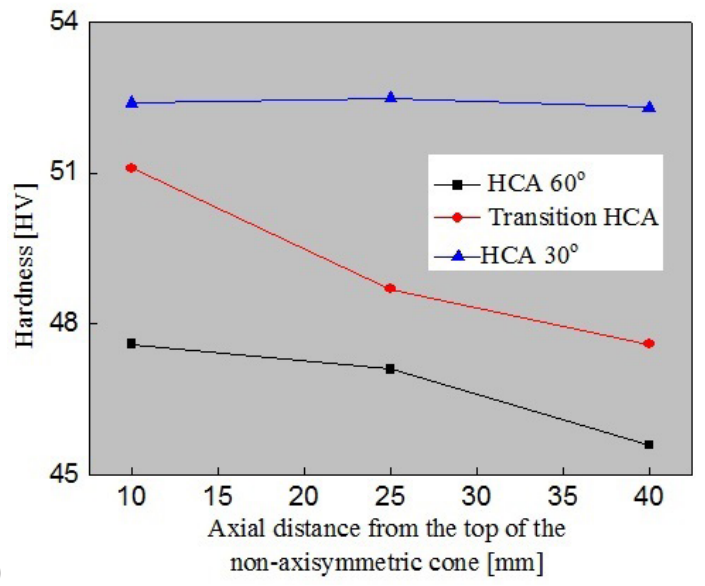

b)

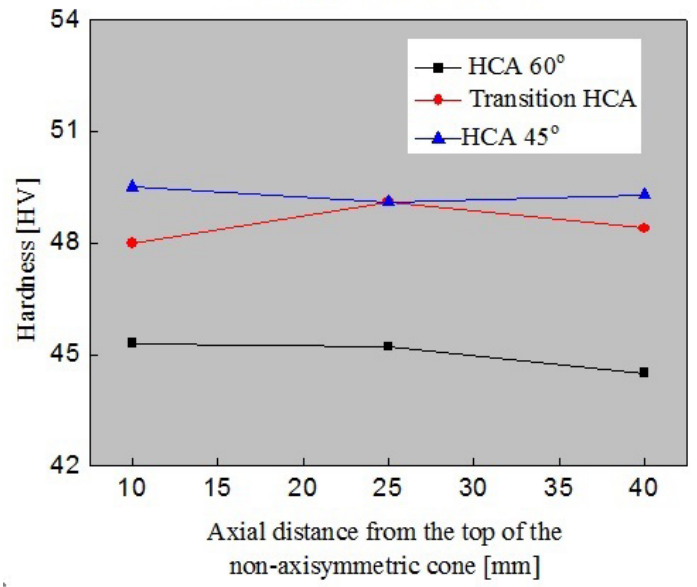

Fig. 7. Hardness distributions of the workpieces under the three working conditions; a) working condition I; b) working condition II;

c) working condition III

\subsection{Establishment of the Finite Element Model}

In order to simulate the non-axisymmetric die-less spinning process, a FEM must first be established. The movement relationship between the roller and the workpiece is the main boundary condition of the 


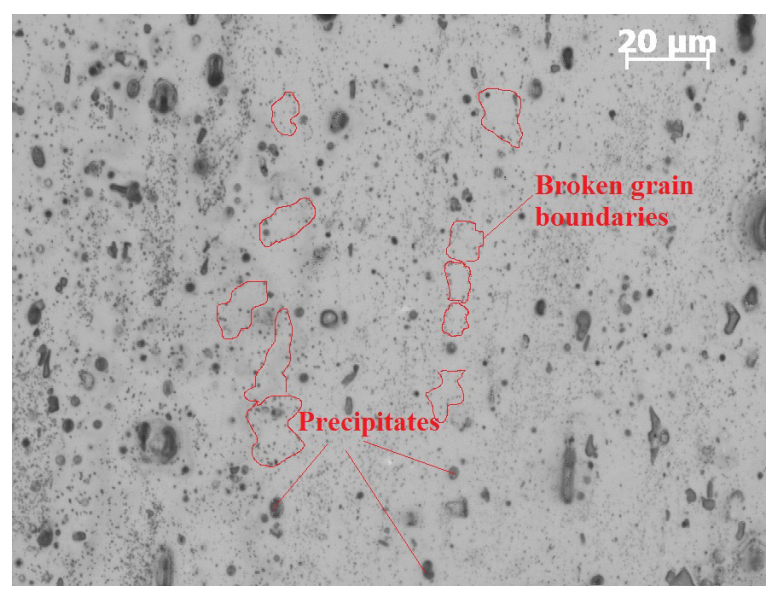

Fig. 8. Metallographic photo of the specimen

model, and it is set in agreement with the experiments by using Eqs. (1) to (3). Then the three-dimensional geometric models of disk blank, tail cap, spindle, and roller are established and assembled in the ABAQUS finite element software (see Fig. 9). All the geometric models are meshed. The roller, tail cap and spindle are arranged in rigid bodies. By considering that there is no deformation happening to the part that is clamped by the tail cap and the spindle, this part of the blank is also constrained into a rigid body. Furthermore, it is driven to rotate with the spindle synchronously. The suspended part of the disk blank is set into a deformable body and meshed with an 8-node linear brick, reduced integration, hourglass control element (C3D8R) for the accurate calculation for the stressstrain. The maximum length of the mesh is $3 \mathrm{~mm}$, and the minimum one is $1 \mathrm{~mm}$. The rotation centre of the roller can move in the plane $X-Z$ of the spinning coordinate system (see Fig. 9), and the roller is also driven to rotate around its rotation centre by the friction from the blank. The friction coefficient is set to the value of 0.15 according to the experience value of oil lubrication. The other spinning conditions of the FEM are set up the same as the experiments.

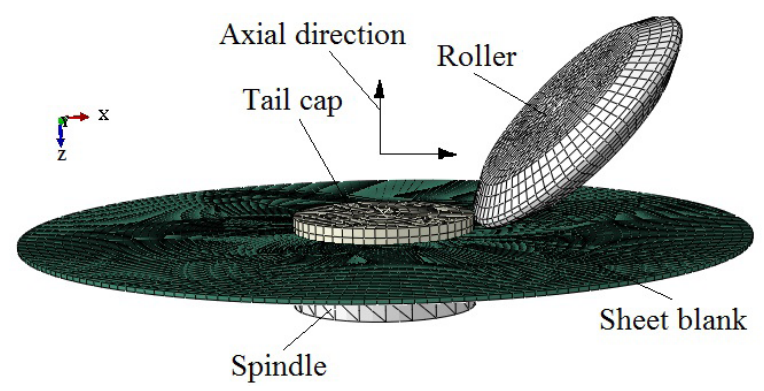

Fig. 9. Assembly diagram of the FEM for the non-axisymmetric die-less spinning
The material of the blank is 6061 aluminium alloy and its elastic modulus is $67000 \mathrm{MPa}$, Poisson ratio is 0.33 , yield strength is $51.59 \mathrm{MPa}$, and tensile strength is $146.12 \mathrm{MPa}$. The constitutive relation of the material is obtained from [4]:

$$
\sigma_{f}=234 \varepsilon^{0.26},
$$

where, $\sigma_{f}$ is the flow stress and $\varepsilon$ is the true strain.

\section{SIMULATION RESULTS}

The morphology of modelling result, in comparison with the experimental one, is shown in Fig. 10. It shows that the simulated results are well consistent with the experimental ones. A further contrast of the HCAs is carried out, as shown in Table 2. It can be found that all the HCAs appear to be close to the theoretical size, and the maximum error occurs in the $\gamma$ of working condition II from the simulation; it can reach $16.3 \%$. The maximum deviation of the HCAs between the experimental and simulation results is no more than $11 \%$. In addition, the simulated wall thickness distribution is compared with the experimental one, and the measuring positions in the working condition I are shown in Fig. 11 together with the ones in the working conditions II and III (the measuring positions also distributed evenly along the HCA direction in the other working conditions). All the measurements of the wall thickness are listed in Table 3. It shows that the simulations agree well with the experiments and the maximum deviation is within $15.1 \%$ in the three working conditions. This indicates that the FEM for the non-axisymmetric die-less spinning is considered credible.

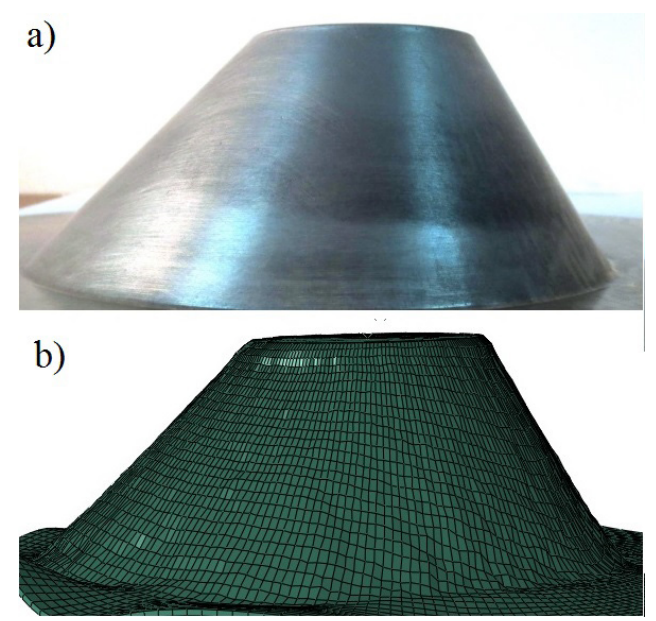

Fig. 10. Morphology comparison of the simulation and experimental results in working condition I; a) Experimental result; b) Simulation result 
Table 2. HCAs of the simulation and experimental results

\begin{tabular}{lcccc}
\hline \multirow{2}{*}{ Experimental result } & \multirow{2}{*}{ HCA } & \multicolumn{3}{c}{ Working condition } \\
\cline { 2 - 5 } & & I & II & III \\
\hline \multirow{2}{*}{ Simulation result } & $\alpha\left[^{\circ}\right]$ & 45.9 & 57.4 & 59.1 \\
\hline & $\gamma\left[^{\circ}\right]$ & 31.5 & 31.4 & 45.6 \\
\hline & $\alpha\left[^{\circ}\right]$ & 47.7 & 60.4 & 62.5 \\
\hline & $\gamma\left[^{\circ}\right]$ & 32.7 & 34.9 & 46.9 \\
\hline & & & & \\
\hline
\end{tabular}

Fig. 11. Measuring positions of the wall thickness

Table 3. Measurements of the wall thickness [mm]

\begin{tabular}{ccccccc}
\hline \multirow{2}{*}{$\begin{array}{c}\text { Axial } \\
\text { height }\end{array}$} & \multicolumn{6}{c}{ Working condition } \\
\cline { 2 - 7 }$[\mathrm{mm}]$ & \multicolumn{2}{c}{ । } & \multicolumn{3}{c}{$\|$} \\
\cline { 2 - 7 } & $\alpha=45^{\circ}$ & $\gamma=30^{\circ}$ & $\alpha=60^{\circ}$ & $\gamma=30^{\circ}$ & $\alpha=60^{\circ}$ & $\gamma=45^{\circ}$ \\
\hline 8 & 0.71 & 0.53 & 0.98 & 0.57 & 1 & 0.73 \\
\hline 15 & 0.71 & 0.56 & 0.96 & 0.57 & 0.98 & 0.73 \\
\hline 22 & 0.71 & 0.56 & 0.99 & 0.56 & 0.98 & 0.73 \\
\hline 29 & 0.71 & 0.56 & 0.97 & 0.57 & 1 & 0.72 \\
\hline 36 & 0.71 & 0.53 & 0.97 & 0.56 & 0.98 & 0.72 \\
\hline 43 & 0.71 & 0.56 & 0.97 & 0.56 & 0.98 & 0.72 \\
\hline
\end{tabular}

\section{DISCUSSION}

The wall thickness distribution of the three working conditions from the simulation are illustrated in Fig. 12. Tensile stress increases with the decreasing of HCA. However, the wall thickness becomes thinner with the decreasing of HCA. This also means the smaller HCA causes larger plastic strain.

Fig. 13 shows the equivalent strain field on the workpiece at the spinning times of $24 \mathrm{~s}, 48 \mathrm{~s}$, and 74 s. It can be found that the deformation is obviously uniform in the non-axisymmetric spinning process, and the uneven degree of the deformation increases with the spinning process. When the plastic strain achieves maximum with the smallest HCA in working condition I and II, the hardness is precisely the biggest one $(51.9 \mathrm{HV}$, the average value of the hardness with the same HCA (Working condition I, $\gamma=30^{\circ}$ ); 52.4

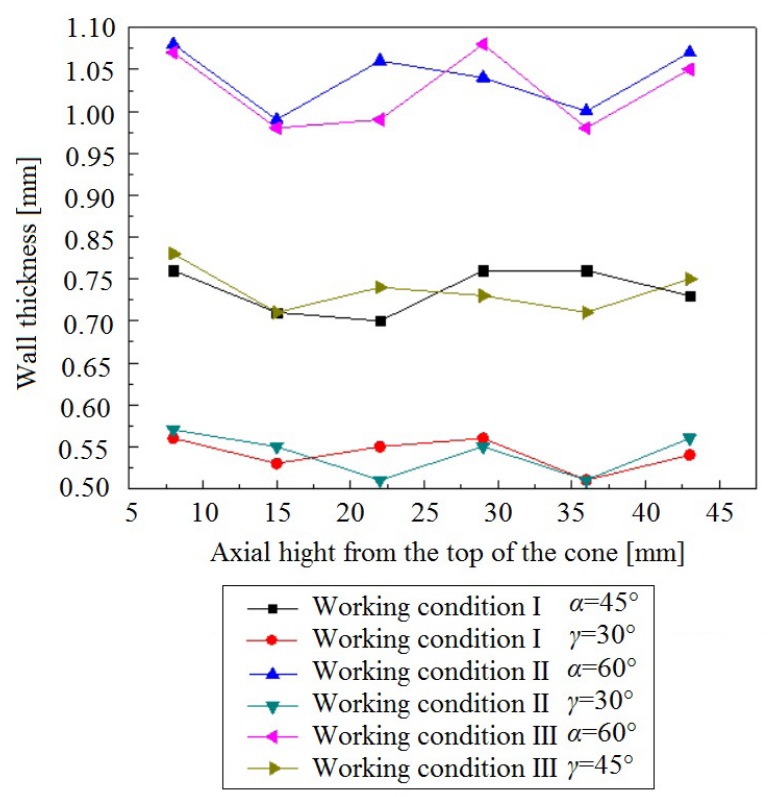

Fig. 12. Comparison of the wall thickness distributions in the three working conditions

$\mathrm{HV}$, the average value of the hardness with the same HCA (Working condition II, $\gamma=30^{\circ}$ ). In order to reveal "smaller HCA with bigger work-hardening", the movement of the non-axisymmetric spinning is resolved by steps. The non-axisymmetric cone can be seen as an aggregate of numerous sheets with the eccentric circular cross-section, and it is spun layer by layer. Fig. 14 displays the roller path between two layers. Moreover, it is defined that as the roller starts from the upper layer to the lower one, the workpiece rotates $360^{\circ}$. In the first $180^{\circ}$, the roller moves far away from the rotation centre in the radial direction and the bigger HCA $\alpha$ is formed; then the roller moves close to the rotation centre at the radial direction in the next $180^{\circ}$ as it gets down to the lower layer and the smaller HCA $\gamma$ being formed. In the forming process of $\gamma$, the blank suffers increasing pressure from the roller and this leads to more uniform deformation. WANG et al. [19] point out that the non-uniformity of plastic strain will directly affect the orientation of the dislocation movement, and promote the formation of the deformation band, which leads to the workhardening of the material. Therefore, the greater workhardening occurs at the position with smaller HCA.

The largest difference of the HCA exists in working condition II, so there is the most uneven deformation on the workpiece of it, and it also has the biggest surface hardness difference (the maximum hardness differences of working condition I, II and III are $9.2 \%, 15.1 \%$ and $11.2 \%$ ). This interesting 


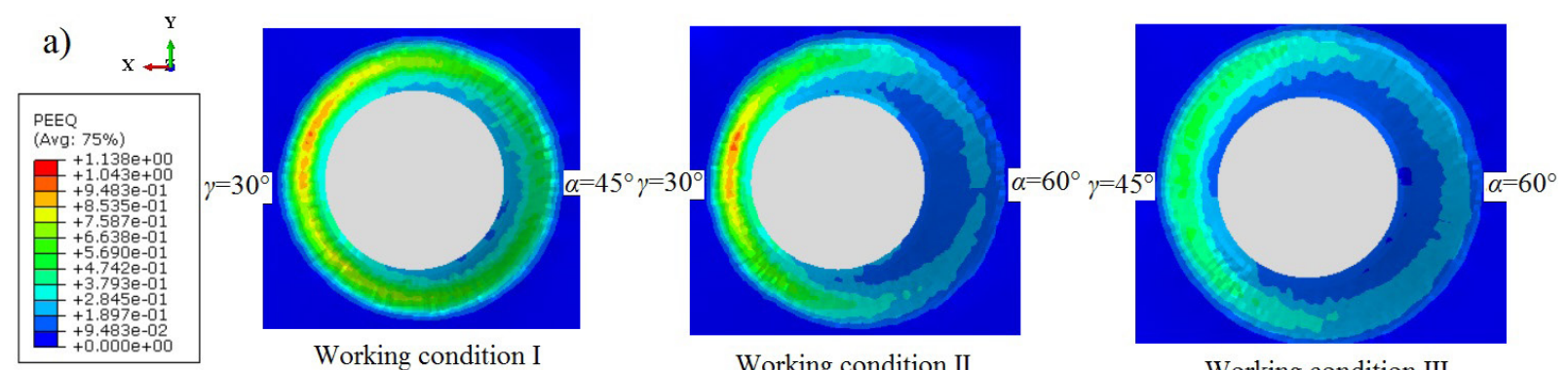

Working condition I

Working condition II

Working condition III

b)

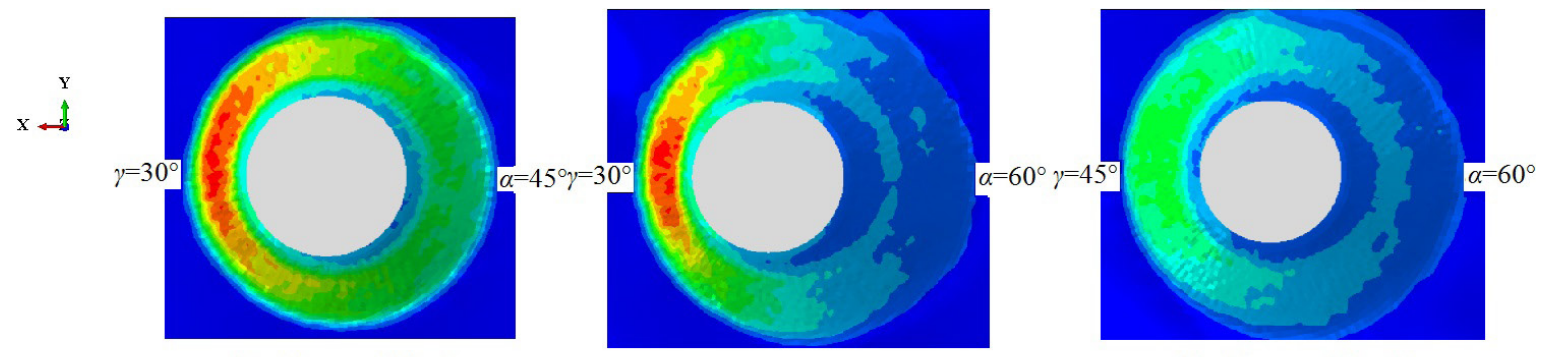

Working condition I

Working condition II

Working condition III

c)

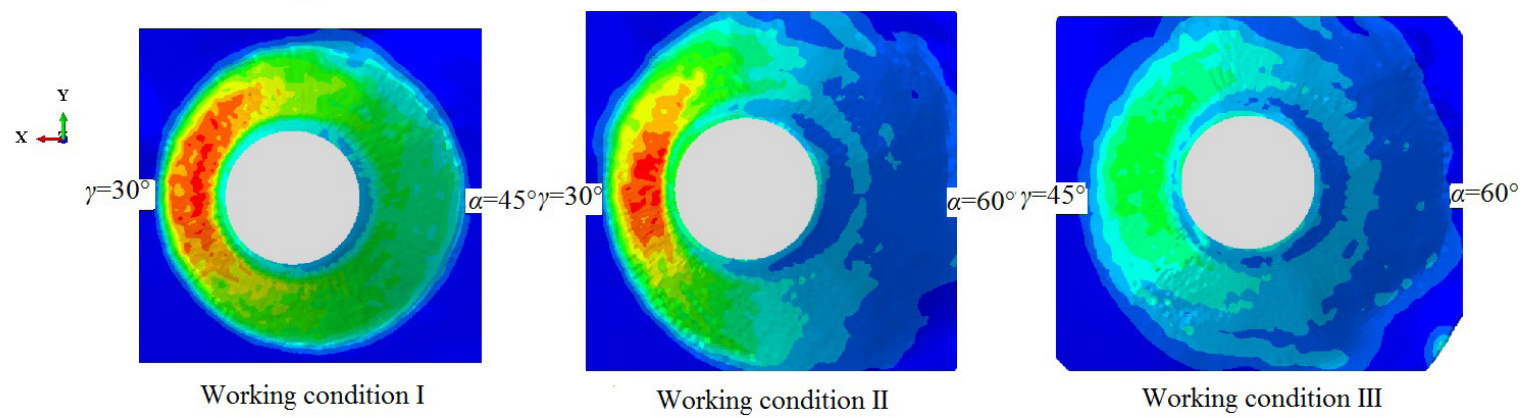

Fig. 13. Equivalent strain field of the non-axisymmetric die-less spinning; a) spinning time $24 \mathrm{~s}$; b) spinning time $48 \mathrm{~s}$; c) spinning time $74 \mathrm{~s}$

phenomenon also confirms the above analysis: greater work-hardening is caused by greater non-uniformity of deformation.

\section{CONCLUSIONS}

Three working conditions of non-axisymmetric dieless spinning experiments are carried out, and the work-hardening distributions of the workpieces are obtained by the surface hardness testing. It is found that the work-hardening distribution of nonaxisymmetric die-less spinning is uneven, and bigger work-hardening appears on the position with smaller HCA. The reason for "smaller HCA with bigger workhardening" is revealed through finite element method: when the smaller HCA is formed, the deformation is more uniform due to the increasing pressure from the roller. The working condition with the largest HCA difference has the biggest wok-hardening difference, and the maximum hardness difference can reach $15 \%$.

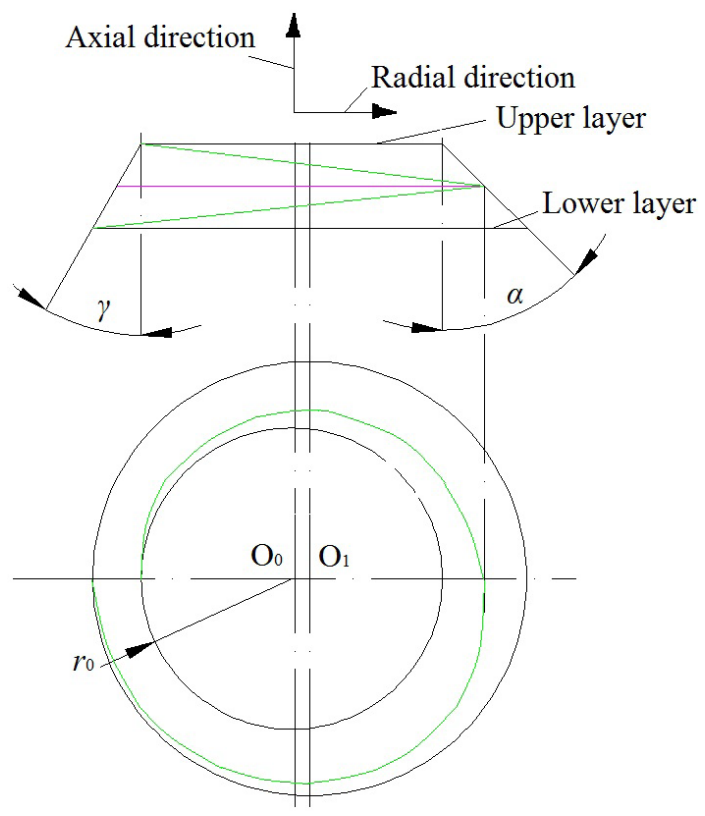

Fig. 14. Roller path between two layers 


\section{ACKNOWLEDGEMENTS}

This work was financially supported by the Natural Science Foundation of Liaoning Province, China (No. 201602558), and authors wish to express their gratitude.

\section{REFERENCES}

[1] Zhan, M., Yang, H., Guo, J., Wang, X.X. (2015). Review on hot spinning for difficult-to-deform lightweight metals. Transactions of Nonferrous Metals Society of China, vol. 25, no. 6, p. 1732-1743, D0l:10.1016/S1003-6326(15)63778-5.

[2] Xia, Q., Xiao, G., Long, H., Cheng, X., Sheng, X. (2014). A review of process advancement of novel metal spinning. International Journal of Machine Tools and Manufacture, vol. 85, p. 100121, D0l:10.1016/j.jjmachtools.2014.-05.005.

[3] Han, D., Yang, H., Zhang, L.W., Mou, S.Z., Yang, Y.T., XiaoXing, H.E. (2010). Effects of heat treatment and spinning temperature on microstructure and properties of $3 \mathrm{~A} 21$ aluminum alloy. Journal of Solid Rocket Technology, vol. 33, no. 2, p. 225-228. (in Chinese)

[4] Xia, Q.X., Xie, S.W., Huo, Y.L., Ruan, F. (2008). Numerical simulation and experimental research on the multi-pass neck-spinning of non-axisymmetric offset tube. Journal of Materials Processing Technology, vol. 206, no.1-3, p. 500508, D0I:1016/J.jmatprotec.2007.12.066.

[5] Xia, Q.X., Cheng, X.Q., Hu, Y., Ruan, F. (2006). Finite element simulation and experimental investigation on the forming forces of 3D non-axisymmetrical tubes spinning. International Journal of Mechanical Sciences, vol. 48, no. 7, p. 726-735, DOl:10.1016/j.jijmecsci.2006.01.014.

[6] Xia, Q.X. (2004). Investigation on the mechanism of the spinning technology of the 3D non-axisymmetric parts. Chinese Journal of Mechanical Engineering, vol. 40, vo. 2, p. 153-156, D0I:10.3901/JME.2004.02.153. (in Chinese)

[7] Awiszus, B., Härtel, S. (2011). Numerical simulation of noncircular spinning: a rotationally non-symmetric spinning process. Production Engineering, vol. 5, no. 6, p. 605-612, DOI:10.1007/s11740-011-0335-9.

[8] Härtel, S., Laue, R. (2015). An optimization approach in noncircular spinning. Journal of Materials Processing Technology, vol. 229, p. 417-430, D0I:10.1016/j.jmatprotec.2015.09.-003.
[9] Music, O., Allwood, J.M. (2011). Flexible asymmetric spinning. CIRP Annals - Manufacturing Technology, vol. 60, no. 1, p. 319-322, DOI: 10.1016/j.cirp.2011.03.136.

[10] Sugita, Y., Arai, H. (2015). Formability in synchronous multipass spinning using simple pass set. Journal of Materials Processing Technology, vol. 217, p. 336-344, D0l:10.1016/j. jmatprotec.2014.11.017.

[11] Zhan, M., Wang, Q.L., Han, D., Yang, H. (2013). Geometric precision and microstructure evolution of TA15 alloy by hot shear spinning. Transactions of Nonferrous Metals Society of China, vol. 23, no. 6, p. 1617-1627, D0l:10.1016/S10036326(13)-62639-4.

[12] Radović, L., Nikačević, M., Jordović, B. (2012). Deformation behaviour and microstructure evolution of AlMg6Mn alloy during shear spinning. Transactions of Nonferrous Metals Society of China, vol. 22, no. 5, p. 991-1000, Dol:10.1016/ S1003-6326(11)61275-2.

[13] Yang, B.J., Xia, Q.X., Cheng, X.Q. (2012). Investigation on fabrication of ultrafine-grain tubular part through power spinning. Journal of Functional Materials, no. 2, p. 266-269. (in Chinese)

[14] Xia, Q., Xiao, G., Long, H., Cheng, X., Yang, B. (2014). A study of manufacturing tubes with nano/ultrafine grain structure by stagger spinning. Materials and Design, vol. 59, p. 516-523, DOI:10.1016/j.matdes.2014.03.012.

[15] Xiao, G., Xia, Q., Cheng, X., Zhou, Y. (2015). Research on the grain refinement method of cylindrical parts by power spinning. The International Journal of Advanced Manufacturing Technology, vol. 78, no. 5, p. 971-979, Dol:10.1007/s00170014-6686-6.

[16] Lu, J., Zeng, X., Ding, W. (2008). The Hall-Petch relationship. Light Metals, vol. 8, p. 59-64. (in Chinese)

[17] Han, Z.R., Xu, Q., Jia, Z., Li, X.B. (2015). Experimental research on oblique cone die-less shear spinning. Proceedings of the Institution of Mechanical Engineers, Part B: Journal of Engineering Manufacture, vol. 78, no. 23, p. 11772-11782, DOI:10.1177/0954405415586607.

[18] Luo, X., Shi, Q.N., Liu, S.H., Chen, Y.L., Wang, X.Q. (2009). Study on microstructure and properties of ultra-fine-grain 6061 aluminium alloy. Transactions of Materials and Heat Treatment, vol. 30, no. 3, p. 71-75. (in Chinese)

[19] Wang, X., Jiang, C., Han, X. (2015). Plastic strain heterogeneity and work hardening of Ni single crystals. Acta Metallurgica Sinica, vol. 51, no. 12, p. 1457-1464. (in Chinese) 